\title{
Albumin as a Delivery Carrier for Rheumatoid Arthritis
}

\author{
Ke Ren', Anand Dusad', Rui Dong² and Lingdong Quan ${ }^{3 *}$ \\ ${ }^{1}$ University of Nebraska Medical Center, Omaha, NE, USA \\ ${ }^{2}$ The Affiliated Hospital of Stomatology, Tianjin Medical University, Tianjin, China
}

${ }^{3}$ Hospital for Special Surgery, New York City, USA

\begin{abstract}
Rheumatoid Arthritis (RA) is a chronic autoimmune disease and considered to be one of the major public health problems worldwide. In the past decade numerous drug delivery systems have been developed to improve the treatment outcome of RA. A stable endogenous protein, albumin has been employed as a non-immunogenic delivery carrier and extensively researched in various disease therapies. To provide the prospective for future research, this review summarizes the application of albumin as drug or imaging agent carriers for RA and proposes potential future directions. There are three major types of albumin-based carrier systems for RA, including albumin drug conjugates, albumin particles and genetic infusion albumin. Their imaging or therapeutic effects have been proved in clinic or preclinical studies.
\end{abstract}

Keywords: Albumin; Rheumatoid arthritis; Inflammation; Delivery carrier

\section{Introduction}

Albumin is the most abundant protein in plasma, accounting for more than half of human plasma protein [1]. It is important for various physiological processes such as providing colloidal osmotic pressure, solubilizing long chain fatty acids, delivery of nutrients to cells, and balancing plasma $\mathrm{pH}$. Albumin has been widely studied as a protein carrier for drug delivery. Currently, there are around seven albuminbased drugs or imaging agents on market (Table 1) and more than ten products under clinical trials $[1,2]$. They have various applications including oncology, diabetes, hepatitis $\mathrm{C}$ and rheumatoid arthritis. There are several advantages of using albumin as drug carrier: 1) as an endogenous protein, Human Serum Albumin (HSA) is native to the body. It is biodegradable in nature, nontoxic and non-immunogenic; 2) Albumin is a robust protein. It is stable over a wide $\mathrm{pH}$ range (4-9), could be heated at $60^{\circ} \mathrm{C}$ for up to $10 \mathrm{~h}$ without deleterious effect, is unaltered by denaturing agents and solvents at moderate concentrations $[3,4]$. Therefore, albumin could remain stable under typical processing conditions; 3) as the most abundant protein in plasma, albumin is readily available. It has been used in clinical setting for more than 30 years; 4 ) the half life of albumin is 19 days in blood circulation. It may play an important role as a carrier in improving the pharmacokinetic property of small drug molecules, peptides or protein based drugs.

Rheumatoid arthritis (RA) is a chronic inflammatory disease that affects a large number of people throughout the world. Uncontrolled active rheumatoid arthritis causes joint damage, disability, and decreased quality of life along with other co-morbidities. The metabolism of synovial cells is highly up-regulated in RA patients $[5,6]$. The uptake of albumin is probably a relevant source of covering their high demand for nitrogen and energy. Therefore, patients with active rheumatoid arthritis frequently have high albumin consumption at sites of inflammation and therefore develop hypoalbuminemia $[7,8]$.

Meanwhile, there is increased permeability of the blood vessels in the inflamed joints $[9,10]$. The fenestration allows for the extravasation of macromolecules at the inflammation site. It has been shown that fluorescein or ${ }^{111}$ In labeled albumin preferentially accumulate at paws affected by RA in a mouse model [11]. Therefore, albumin is an attractive carrier targeting inflamed joints. There are three major types of albumin-based delivery systems for RA.

\section{Albumin-Drug Conjugate}

Methotrexate (MTX) is a common used drug for treating RA and cancer. To overcome the lack of specificity with regard to the inflamed tissue as well as increasing the half life, methotrexate-albumin conjugate (MTX-HSA) was developed by directly coupling MTX to lysine residues of HSA. Compared with equivalent dosage of MTX, MTX-HSA was more effective in a collagen-induced arthritis mouse model [11]. Meanwhile, MTX-HSA has shown to significantly reduce synovial fibroblast invasion and cartilage degradation in a humanized rheumatoid arthritis model using severe combined immunodeficient mice [12]

Besides MTX-HSA, an albumin-binding prodrug of MTX was also developed. After intravenous application, EMC-d-Ala-Phe-Lys-LysMTX (EMC= 6-maleimidocaproic acid, AWO54) could rapidly and selectively bind to the cysteine-34 position of endogenous albumin to form a stable conjugate in human plasma. The conjugate is cleaved by cathepsin B and plasmin, two proteases that are over expressed at arthritic sites, and release a MTX lysine derivative [13]. The conjugate had a significantly better anti-arthritic effect than MTX in a murine collagen-induced arthritis model, especially for late stage RA [14].

Currently, HSA-MTX is the only drug candidate conjugated with albumin for RA treatments. There are many albumin drug conjugates developed for other diseases, such exendin- 4 albumin conjugate for diabetes (in clinical trial). Coupling other anti-inflammatory drugs with albumin for RA treatment is a research area worth exploring.

\section{Albumin Particles}

Albumin microcapsules were developed for delivering anti-

*Corresponding author: Lingdong Quan, Arthritis and Tissue Degeneration Program, Hospital for Special Surgery, 535 East 70th Street, New York, NY 10021, USA, Tel: 212-774-2529; E-mail: quanlingdong@gmail.com

Received May 08, 2013; Accepted June 13, 2013; Published June 15, 2013

Citation: Ren K, Dusad A, Dong R, Quan L (2013) Albumin as a Delivery Carrier for Rheumatoid Arthritis. J Nanomed Nanotechol 4: 176. doi:10.4172/21577439.1000176

Copyright: (c) 2013 Ren K, et al. This is an open-access article distributed under the terms of the Creative Commons Attribution License, which permits unrestricted use, distribution, and reproduction in any medium, provided the original author and source are credited. 


\begin{tabular}{|c|c|c|c|}
\hline Product & Drug & indication & Current status \\
\hline ABI-007 (Abraxane $\left.{ }^{\circledR}\right)$ & Albumin-paclitaxel nanoparticle & Oncology & Marketed \\
\hline${ }^{99 m}$ Tc-Albures & ${ }^{99 m}$ Tc -aggregated albumin & Oncology & Marketed \\
\hline 99mTc-Nanocoll & 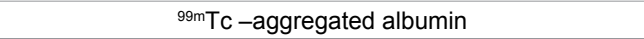 & Oncology & Marketed \\
\hline Vasovist $^{\circledR}$ & Albumin-binding Gadolinium (III) complex & Oncology & Marketed \\
\hline B-22956/1 & Albumin-binding Gadolinium (III) complex & Oncology & Marketed \\
\hline Levenir $^{\circledast}$ & Albumin-binding fatty acid derivative of insulin & Diabetes & Marketed \\
\hline Liraglutide $\left(\right.$ Victoza $\left.{ }^{\circledR}\right)$ & Albumin-binding fatty acid derivative of GLP-1 & Diabetes & Marketed \\
\hline Albuferon $^{\circledR}$ & Albumin-fusion protein of interferon- $a-2 b$ & Hepatitis C & Phase III \\
\hline AT-103 (Ozoralizumab) & Albumin-binding nanobody directed against human TNF- $\alpha$ & Rheumatology & Phase II \\
\hline INNO-206 & Albumin binding prodrug of doxorubicin & Oncology & Phase II \\
\hline $\mathrm{ABI}-008$ & Albumin-docetaxel nanoparticle & Oncology & Phase II \\
\hline MTX-HSA & Methotrexate albumin conjugate & Oncology & Phase I/II \\
\hline MM-111 & Albumin fusion protein directed against ErbB2 and ErbB3 & Oncology & Phase I/II \\
\hline AFL-HSA & Albumin conjugate of aminofluorescein & Oncology & Phase I/II \\
\hline CjC-1134-PC & Albumin conjugate of exendin- 4 & Diabetes & Phase $\mathrm{I} / \mathrm{II}$ \\
\hline ABI-009 & Albumin-rapamycin nanoparticle & Oncology & Phase I \\
\hline ABI-010 & Albumin nanoparticle with a HSP90 inhibitor & Oncology & Phase I \\
\hline
\end{tabular}

Table 1: Albumin-based drugs or imaging agents on market and under clinical trials.

inflammatory drugs [15]. Generally, the microspheres were produced by chemically linking albumin using glutaraldehyde or by addition of an organic solvent and stabilization at high temperatures. The size of the microspheres was usually in a range of 1-100 $\mu \mathrm{m}$. The drug was dispersed through the albumin matrix and released continuously as the microcapsules were degraded by intracellular proteolytic enzymes [16,17]. After encapsulating an antisense NF-kappaB oligonucleotide, the albumin microsphere could effectively reduce the paw swelling in a rat RA model. Meanwhile, long-term use of these microspheres was non-toxic and there were no observable allergic reactions in the rats $[18,19]$.

Albumin nanoparticles have been extensively researched for cancer treatment. Albumin-paclitaxel nanoparticle (Abraxane ${ }^{\mathrm{nt}}$ ) is commercially available, whereas albumin-docetaxel nanoparticle and albumin-rapamycin nanoparticles are in clinical trials [1]. The albumin matrix effectively incorporates drugs or electrostatically adsorbs charged molecules (including gene) because of the high content of charged amino acids (eg. lysine) in albumin. In addition, the presence of functional groups (amino and carboxylic groups) on the nanoparticle surface makes it possible to conjugate targeting ligands.

Aspirin loaded albumin nanoparticles were prepared by coacervation method. The particle size ranged from $47-191 \mathrm{~nm}$ with an aspirin/albumin ratio of 0.06-1.0 [20]. Aspirin was released from the nanoparticle at a sustained rate for prolonged duration with $50 \%$ total cumulative release at the end of 20 hours [20]. However, there is no in vivo data evaluating the therapeutic effects. Another albumin-based nanoparticle based on active targeting mechanism was also developed. Folate receptor beta $(\mathrm{FR} \beta)$ is specifically expressed on activated macrophages in inflamed joints, and therefore is used as a target for drug delivery in RA [21,22]. Both therapeutics and imaging agents based on folate modified nanoparticles have been developed and their efficacies have been proved in vivo in RA model $[23,24]$. Rollett A et al. [25] developed folic acid-functionalized HSA nanocapsules with size around $440 \mathrm{~nm}$ and a narrow distribution. In vitro cell culture study showed specific binding and internalization of the HSA nanoparticles by FR $\beta$-positive macrophages. Future investigations loading different anti-inflammatory drugs and further therapeutic evaluation for the treatment of RA are needed.

Besides therapeutic drugs, albumin-based diagnostic nanoparticles have also been developed. Technetium-99m $\left({ }^{99 m} \mathrm{Tc}\right)$ is a metastable nuclear isomer widely used for medical diagnostics. ${ }^{99 \mathrm{~m}} \mathrm{Tc}$-labeled human serum albumin is used in nuclear medicine for diagnosing various conditions including cancer and infectious diseases [26,27]. Many preparation kits for this formulations are available on market from a number of manufacturers, such as ${ }^{99 \mathrm{~m}} \mathrm{Tc}-\mathrm{Nanocoll}^{\mathbb{Q}},{ }^{99 \mathrm{~m}} \mathrm{Tc}$ Albures ${ }^{\circledR}$ and ${ }^{99 \mathrm{~m}} \mathrm{Tc}$ - Human Serum Albumin ${ }^{\circledR}$. In these formulations, the human serum albumin aggregated particles has a wide range of size from a few $\mathrm{nm}$ to up to $1000 \mathrm{~nm}$ depending on the application. The precise structures of the aggregated albumin complexes are currently unknown. There are many reports using ${ }^{99 \mathrm{~m}} \mathrm{Tc}$-albumin nanocolloid in diagnosing arthritis in both animals [28] and patients [29-31].

\section{Albumin Fusion Protein}

The pro-inflammatory cytokines play a vital role in the development of rheumatoid arthritis. TNF- $\alpha$ is one of the key inflammatory cytokines. Modulation of TNF- $\alpha$ has been proved to be an effective treatment for rheumatoid arthritis. There are four anti-TNF- $\alpha$ antibodies on market, including Enebrel $^{\circledR}$ (etanercept), Remicade ${ }^{\circledR}$ (infliximab), Humira $^{\circledR}$ (adalimumab)and Cimzia ${ }^{\circledR}$ (Certolizumabpegol). A novel type of anti-TNF- $\alpha$ antibody based on albumin was developed. The camelid anti-TNF- $a$-anti-HSA trivalent nanobody is composed of two anti-TNF- $\alpha$ domains and one anti-HSA domain. This novel trivalent bispecific antibody showed significant therapeutic effect in RA animal models. The using of albumin as carrier significantly prolonged the serum half-life and promoted the targeting to inflamed joints [11,32]. Currently, this novel antibody (Ozralizumab) is under phase II clinical trial for treating RA.

Another important proinflammatory cytokine for RA is interleukin-1 (IL-1) [33]. IL-1 receptor antagonist (IL-1ra) is a naturally occurring cytokine that blocks biological activity of IL-1via binding to IL-1 type I receptor with the same affinity as that of IL- $1 \beta$. Recombinant human IL-1ra (rhIL-1ra), Anakinra, has been approved for the treatment of patients with moderate-severe RA. However, Anakinra exhibits rapid clearance from the circulatory system and poor retention in the inflamed joint. To solve these problems, genetic fusion protein composed of IL-1ra and HSA was developed. The plasma half life of IL-1ra was extended to more than 30 -fold and selectively accumulated in the inflamed joints of a collagen-induced mouse RA model [34]. 


\section{Conclusion and Future Directions}

The above mentioned studies have demonstrated inspiring effects of using albumin as carriers for RA. There are many common pathophysiological features among inflammatory diseases, including vasculature restructuring, inflammatory cell recruitment and elevated inflammatory cytokines [10]. The enhanced vascular fenestration allows albumin-based delivery systems to extravasate at the inflammation site. The albumin systems developed for RA might be applicable to other inflammatory diseases because of this passive-targeting mechanism. Meanwhile, as there are lots of albumin-based delivery systems developed for other diseases, these systems might also be applied to RA. For example, the albumin-binding gadolinium complexes based MRI contrast agents Vasovist ${ }^{\mathbb{B}}$ for cancer may also be used for RA diagnose. The albumin microencapsulated dexamethasone which has been developed for infection disease might be potent in treating RA since the therapeutic effect of dexamethasone in treating arthritis has been widely proved [35]. More anti-inflammatory drugs may also be conjugate with albumin or incorporated into albumin particles to increase their therapeutic efficacies and decrease side effects. In addition to folate, other inflammation targeting moieties may also be employed to increase the therapeutic efficacy to RA. As a versatile carrier, there are many exciting avenues for the application of albumin in treating RA and other inflammatory diseases that have not been fully explored.

\section{References}

1. Kratz F, Elsadek B (2012) Clinical impact of serum proteins on drug delivery. J Control Release 161: 429-445.

2. Elsadek B, Kratz F (2012) Impact of albumin on drug delivery--new applications on the horizon. J Control Release 157: 4-28.

3. Neumann E, Frei E, Funk D, Becker MD, Schrenk HH, et al. (2010) Native albumin for targeted drug delivery. Expert Opin Drug Deliv 7: 915-925.

4. Kratz F (2008) Albumin as a drug carrier: design of prodrugs, drug conjugates and nanoparticles. J Control Release 132: 171-183.

5. van de Stadt RJ, van de Voorde-Vissers E, Feltkamp-Vroom TM (1980) Metabolic and secretory properties of peripheral and synovial granulocytes in rheumatoid arthritis. Arthritis Rheum 23: 17-23.

6. Henderson B, Bitensky L, Johnstone JJ, Catterall A, Chayen J (1979) Metabolic alterations in human synovial lining cells in pigmented villonodular synovitis. Ann Rheum Dis 38: 463-466.

7. Wilkinson $P$, Jeremy R, Brooks FP, Hollander JL (1965) The mechanism of hypoalbuminemia in rheumatoid arthritis. Ann Intern Med 63: 109-114.

8. Ballantyne FC, Fleck A, Dick WC (1971) Albumin metabolism in rheumatoid arthritis. Ann Rheum Dis 30: 265-270.

9. Levick JR (1981) Permeability of rheumatoid and normal human synovium to specific plasma proteins. Arthritis Rheum 24: 1550-1560.

10. Henson PM (2005) Dampening inflammation. Nat Immunol 6: 1179-1181.

11. Wunder A, Muller-Ladner U, Stelzer EH, Funk J, Neumann E, et al. (2003) Albumin-based drug delivery as novel therapeutic approach for rheumatoid arthritis. J Immunol 170: 4793-4801.

12. Fiehn C, Neumann E, Wunder A, Krienke S, Gay S, et al. (2004) Methotrexate (MTX) and albumin coupled with MTX (MTX-HSA) suppress synovial fibroblas invasion and cartilage degradation in vivo. Ann Rheum Dis 63: 884-886.

13. Warnecke A, Fichtner I, Sass G, Kratz F (2007) Synthesis, cleavage profile and antitumor efficacy of an albumin-binding prodrug of methotrexate that is cleaved by plasmin and cathepsin B. Arch Pharm (Weinheim) 340: 389-395

14. Fiehn C, Kratz F, Sass G, Muller-Ladner U, Neumann E (2008) Targeted drug delivery by in vivo coupling to endogenous albumin: an albumin-binding prodrug of methotrexate (MTX) is better than MTX in the treatment of murine collagen-induced arthritis. Ann Rheum Dis 67: 1188-1191.

15. Oettinger CW, D'Souza MJ (2012) Microencapsulated drug delivery: a new approach to pro-inflammatory cytokine inhibition. J Microencapsul 29: 455-462.
16. Gayakwad SG, Bejugam NK, Akhavein N, Uddin NA, Oettinger CE, et al. (2009) Formulation and in vitro characterization of spray-dried antisense oligonucleotide to NF-kappaB encapsulated albumin microspheres. J Microencapsul 26: 692-700.

17. Siwale RC, Oettinger CW, Pai SB, Addo R, Uddin N, et al. (2009) Formulation and characterization of catalase in albumin microspheres. J Microencapsul 26 411-419.

18. Moreland LW, Baumgartner SW, Schiff MH, Tindall EA, Fleischmann RM, et al. (1997)Treatment of rheumatoid arthritis with a recombinant human tumor necrosis factor receptor (p75)-Fc fusion protein. N Engl J Med 337: 141-147.

19. Akhavein N, Oettinger CW, Gayakwad SG, Addo RT, Bejugam NK, et al (2009) Treatment of adjuvant arthritis using microencapsulated antisense NFKB oligonucleotides. J Microencapsul 26: 223-234.

20. Das S, Banerjee R, Bellare J (2005) Aspirin loaded albumin nanoparticles by coacervation: implications in drug delivery. Trends Biomater Artif Organs 18 203-212.

21. Paulos CM, Turk MJ, Breur GJ, Low PS (2004) Folate receptor-mediated targeting of therapeutic and imaging agents to activated macrophages in rheumatoid arthritis. Adv Drug Deliv Rev 56: 1205-1217.

22. van der Heijden JW, Oerlemans R, Dijkmans BA, Qi H, van der Laken CJ, et al. (2009) Folate receptor beta as a potential delivery route for novel folate antagonists to macrophages in the synovial tissue of rheumatoid arthritis patients. Arthritis Rheum 60: 12-21.

23. Thomas TP, Goonewardena SN, Majoros IJ, Kotlyar A, Cao Z, et al. (2011) Folate-targeted nanoparticles show efficacy in the treatment of inflammatory arthritis. Arthritis Rheum 63: 2671-2680.

24. Turk MJ, Breur GJ, Widmer WR, Paulos CM, Xu LC, et al. (2002) Folatetargeted imaging of activated macrophages in rats with adjuvant-induced arthritis. Arthritis Rheum 46: 1947-1955.

25. Rollett A, Reiter T, Nogueira P, Cardinale M, Loureiro A, et al. (2012) Folic acidfunctionalized human serum albumin nanocapsules for targeted drug delivery to chronically activated macrophages. Int J Pharm 427: 460-466.

26. Rink T, Heuser T, Fitz H, Schroth HJ, Weller E, et al. (2001) Lymphoscintigraphic sentinel node imaging and gamma probe detection in breast cancer with Tc$99 \mathrm{~m}$ nanocolloidal albumin: results of an optimized protocol. Clin Nucl Med 26: 293-298.

27. Wang YF, Chuang MH, Chiu JS, Cham TM, Chung MI (2007) On-site preparation of technetium-99m labeled human serum albumin for clinical application. Tohoku J Exp Med 211: 379-385.

28. Breedveld FC, van Kroonenburgh MJ, Camps JA, Feitsma HI, Markusse HM et al. (1989) Imaging of inflammatory arthritis with technetium-99m-labeled lgG J Nucl Med 30: 2017-2021.

29. Adams BK, Al Attia HM, Khadim RA, Al Haider ZY (2001) 99Tc(m) nanocolloid scintigraphy: a reliable way to detect active joint disease in patients with peripheral joint pain. Nucl Med Commun 22: 315-318.

30. Tishler M, Lysyy O, Levy O, Volkov O, Golan H (2010) 99m Tc-albumin nanocolloid joint scintigraphy in rheumatoid arthritis patients who are in clinical remission - is remission real ? Clin Exp Rheumatol 28: 360-364

31. Liberatore $M$, Clemente M, lurilli AP, Zorzin L, Marini M, et al. (1992) Scintigraphic evaluation of disease activity in rheumatoid arthritis: a comparison of technetium-99m human non-specific immunoglobulins, leucocytes and albumin nanocolloids. Eur J Nucl Med 19: 853-857.

32. Coppieters K, Dreier T, Silence K, de Haard H, Lauwereys M, et al. (2006) Formatted anti-tumor necrosis factor alpha $\mathrm{VHH}$ proteins derived from camelids show superior potency and targeting to inflamed joints in a murine model of collagen-induced arthritis. Arthritis Rheum 54: 1856-1866.

33. Schiff MH (2000) Role of interleukin 1 and interleukin 1 receptor antagonist in the mediation of rheumatoid arthritis. Ann Rheum Dis 59: i103-i108.

34. Liu M, Huang Y, Hu L, Liu G, Hu X, et al. (2012) Selective delivery of interleukine-1 receptor antagonist to inflamed joint by albumin fusion. BMC Biotechnol 12: 68 .

35. Uddin MN, Siddiq A Oettinger CW, D'Souza MJ (2011) Potentiation of proinflammatory cytokine suppression and survival by microencapsulated dexamethasone in the treatment of experimental sepsis. J Drug Target 19 752-760. 